\title{
Comparison of Chest X-rays findings in COVID-19 suspected and confirmed cases at a university teaching hospital: A retrospective comparative study
}

\author{
Misbah Durrani ${ }^{1}$, Afshan Shahid ${ }^{2}$, Ume Kalsoom ${ }^{3}$, \\ Inam-ul-Haq ${ }^{4}$, Anum Yousaf ${ }^{5}$, Saqib Naveed ${ }^{6}$
}

\begin{abstract}
Objectives: To compare Chest X-rays findings in COVID-19 suspected and confirmed patients on RT-PCR, presented at corona filtration center, Benazir Bhutto hospital Rawalpindi.

Methods: In this study, Chest radiographs of 100 COVID-19 RT-PCR positive confirmed patients were compared with 100 RT-PCR negative suspected COVID-19 patients screened at corona filtration center, Benazir Bhutto Hospital Rawalpindi from November 2020 to December 2020. Data on demographics, presenting complaints, co-morbid, lesion characteristic, distribution and attenuation, lobar involvement, pleural effusion and lymphadenopathy were collected. Associations between imaging characteristics and COVID-19 pneumonia were analyzed with univariate and multivariate logistic regression modals.

Results: Chest X-rays findings revealed bilateral lung consolidation with peripheral and diffuse distribution, involving middle and lower lobe to be statistically significant $(p<0.05)$ between RT-PCR positives and negative patients. Peripheral distribution was associated with an 11.08-fold risk in COVID-19 positive patients than diffuse distribution. Middle lobe involvement had four folds risk and lower lobe involvement had 11.04 folds risk in COVID-19 cases as compared to upper lobe involvement. Consolidation had 2.6 folds risk in COVID-19 positive cases.

Conclusions: Bilateral, peripheral distribution of middle and lower lobes ground glass haze or consolidation with no pleural effusion is significantly related to COVID-19 pneumonia. Overlapping imaging features of the infectious and non-infectious COVID mimickers can be further excluded by detailed clinical evaluation and further radiological workup.
\end{abstract}

KEYWORDS: COVID-19 patients, Chest X-rays (CXR), Corona virus, Reverse transcriptase polymerase chain reaction RT-PCR.

doi: https://doi.org/10.12669/pjms.38.1.4624

How to cite this:

Durrani M, Shahid A, Kalsoom U, Inam-ul-Haq, Yousaf A, Naveed S. Comparison of Chest X-rays findings in COVID-19 suspected and confirmed cases at a university teaching hospital: A retrospective comparative study. Pak J Med Sci. 2022;38(1):76-83. doi: https://doi.org/10.12669/pjms.38.1.4624

This is an Open Access article distributed under the terms of the Creative Commons Attribution License (http://creativecommons.org/licenses/by/3.0), which permits unrestricted use, distribution, and reproduction in any medium, provided the original work is properly cited.

\section{INTRODUCTION}

Correspondence:

Dr. Misbah Durrani,

Associate Professor Diagnostic Radiology

Rawalpindi Institute of Cardiology.

Rawalpindi, Pakistan.

E-mail: misbahdurrani73@gmail.com

* Received for Publication:

April 25, 2021

* Revision Received:

* Revision Accepted:
September 1, 2021

September 9, 2021
War against COVID-19 is still raging on as it continues its devastations and pose a major unprecedented health crisis globally. Although in an era of pandemic, every patient with respiratory symptoms like cough, dyspnea, sore throat and fever is considered to be having COVID-19, yet there are other infectious and non-infectious pulmonary diseases which may mimic COVID-19 radiologically. 
HRCT (high resolution computed tomography) is the radiological investigation of choice as it has high sensitivity of $98 \%$ as compared to RTPCR which has a sensitivity of only $60-71 \% .{ }^{1}$ RTPCR has also additional limitations regarding faulty sampling techniques, Kit performance and awaited results. Chest $X$-rays, although having sensitivity of almost $67 \%$ are still used in our public hospitals and rural health centers as first line of investigation as compared to HRCT. Chest X-rays are readily available, affordable, less time consuming in terms rigorous CT decontamination measures and also in terms of expert radiological interpretation by general practitioners and physicians. $^{2}$ It was therefore thought to take RT-PCR as gold standard and to compare CXR findings of COVID-19 RT-PCT positive patients with that of COVID-19 RT-PCR negative patients having similar respiratory symptoms.

\section{METHODS}

This is a retrospective descriptive study was conducted from November 2020 to December 2020 after consent from ethical review board. About 200 patients with clinical suspicion of COVID-19 who visited corona filter clinic at Benazir Bhutto hospital Rawalpindi were included. Chest $X$-rays are stored in central computer server of Benazir Bhutto hospital.Chest radiographs of 100 COVID-19 RT-PCR positive confirmed patients were compared with 100 RTPCR negative patients.

Inclusion criteria:

1. Patients with symptoms suggesting of COVID-19.

2. COVID-19 RT-PCR result.

Exclusion criteria:

1. Normal chest $X$-ray.

2. Non COVID X-ray features like pneumothorax, pulmonary edema, lung cavities/calcifications.

3. Post admission CT chest features suggestive of COVID-19.

Quantitative variables like age are presented as mean with standard deviation. Qualitative variables like gender and co morbidities were presented as frequency and percentages. Symptoms, CXR findings were also presented as frequency and percentages. Group difference and statistical significance was seen by applying chisquare test on all categorical variables. Univariate regression analysis was applied to see the effect size for the relationship among all variables in two groups. Lastly multivariate regression analysis was performed to evaluate the associations between different characteristics and outcome. Model-1 was created by not adjusting any variable, final model adjusted for age, gender, all symptoms, and co morbidities sequentially. A two-tailed p-value of less than .05 was taken as statistically significant. All analysis was done by using SPSS version 23 .

Ethical Approval: Ref. No. 52 /IREF $\backslash$ RMU $\backslash 2020$, Dated: 14-04-2020.

\section{RESULTS}

Two hundred patients were analyzed retrospectively in a tertiary care treatment public sector hospital for COVID-19 in Rawalpindi. Patients were divided in two groups and labelled as COVID-19 positive or negative on the basis of RT-PCR. Mean age of patients in COVID-19 positive group was $45 \pm 15.5$ with $76 \%$ males and $24 \%$ females. Mean age of patients in COVID-19 negative group was $37 \pm 18.1$ with $57 \%$ males and $43 \%$ females. Among the different characteristics of patients investigated in history, presence of co-morbidities and imaging characteristics on X-rays, significant difference was found in gender, history of fever and sore throat, and diabetes. Chest $\mathrm{X}$-rays findings revealed bilateral lung consolidation with peripheral and diffuse distribution, involving middle and lower lobe to be statistically significant $(\mathrm{p}<0.05)$ between RTPCR positives and negative patients. The details of patient's characteristics are shown in Tables-I \& II. Significant association between gender, history of fever, sore throat, diabetes, disease distribution, lobes involvement, consolidation and COVID-19 pneumonia were observed on univariate analysis as shown in Table-III.

Different variables were adjusted according to the Likelihood ratio test depending upon their contribution in the model, peripheral distribution was associated with a 11.08-fold risk in COVID -19 positive patients than diffuse distribution. Middle lobe involvement had four folds risk and lower lobe involvement had 11.04 folds risk in COVID-19 cases as compared to upper lobe involvement. Consolidation had 2.6 folds risk in COVID-19 positive cases. The results of multi variate analysis are shown in Table-III.

\section{DISCUSSION}

COVID-19 is a multifaceted disease with variable presentations and unpredictable outcomes. So, in an era of current pandemic, 
Table-I: Base line characteristics of patients. (Figures are presented as whole numbers with percentages in brackets).

\begin{tabular}{|c|c|c|c|c|}
\hline Characteristics & & COVID-19 Negative & COVID-19 Positive & p-value \\
\hline \multicolumn{5}{|l|}{ Age (years) } \\
\hline Mean \pm SD & & $37 \pm 18.1$ & $45 \pm 15.5$ & \\
\hline \multicolumn{5}{|l|}{ Gender } \\
\hline Male & & $57(57 \%)$ & $76(76 \%)$ & \multirow{2}{*}{0.004} \\
\hline Female & & $43(43 \%)$ & $24(24 \%)$ & \\
\hline \multicolumn{5}{|l|}{ Smoking } \\
\hline & No & $80(80 \%)$ & $83(83 \%)$ & \multirow{2}{*}{0.585} \\
\hline & Yes & $20(20 \%)$ & $17(\%)$ & \\
\hline \multicolumn{5}{|l|}{ Symptoms } \\
\hline \multirow[t]{2}{*}{ Fever } & No & $37(37 \%)$ & $19(19 \%)$ & \multirow[t]{2}{*}{0.005} \\
\hline & Yes & $63(63 \%)$ & $81(81 \%)$ & \\
\hline \multirow[t]{2}{*}{ Cough } & No & $35(35 \%)$ & $38(38 \%)$ & \multirow[t]{2}{*}{0.659} \\
\hline & yes & $65(65 \%)$ & $62(62 \%)$ & \\
\hline \multirow[t]{2}{*}{ Shortness of breath } & No & $60(60 \%)$ & $55(55 \%)$ & \multirow{3}{*}{0.474} \\
\hline & Yes & $40(40 \%)$ & $45(45 \%)$ & \\
\hline \multirow[t]{2}{*}{ Sore throat } & No & $69(69 \%)$ & $13(13 \%)$ & \\
\hline & Yes & $31(31 \%)$ & $87(87 \%)$ & 0.002 \\
\hline \multirow[t]{2}{*}{ Loss of smell } & No & $98(98 \%)$ & $99(99 \%)$ & \multirow[t]{2}{*}{0.561} \\
\hline & Yes & $2(2 \%)$ & $1(1 \%)$ & \\
\hline \multirow[t]{2}{*}{ Loss of taste } & No & $97(97 \%)$ & $96(96 \%)$ & \multirow[b]{2}{*}{.67} \\
\hline & Yes & $03(3 \%)$ & $04(4 \%)$ & \\
\hline \multirow[t]{2}{*}{ Diarrhea } & No & $81(81 \%)$ & $96(96 \%)$ & \multirow{2}{*}{0.001} \\
\hline & Yes & $19(19 \%)$ & $4(4 \%)$ & \\
\hline \multirow[t]{2}{*}{ Travel history } & No & $61(61 \%)$ & $82(82 \%)$ & \multirow[b]{2}{*}{0.001} \\
\hline & Yes & $39(39 \%)$ & $18(18 \%)$ & \\
\hline \multicolumn{5}{|l|}{ Co-morbidities } \\
\hline \multirow[t]{2}{*}{ Diabetes } & No & $85(85 \%)$ & $06(06 \%)$ & \multirow[t]{2}{*}{0.038} \\
\hline & Yes & $15(15 \%)$ & $94(64 \%)$ & \\
\hline \multirow[t]{2}{*}{ Hypertension } & No & $83(83 \%)$ & $38(38 \%)$ & 0.093 \\
\hline & Yes & $17(17 \%)$ & $62(62 \%)$ & \\
\hline CKD & No & $95(95 \%)$ & $97(97 \%)$ & \\
\hline & Yes & $05(05 \%)$ & $03(03 \%)$ & 0.470 \\
\hline Tuberculosis & No & $94(94 \%)$ & $87(87 \%)$ & \\
\hline & Yes & $06(06 \%)$ & $13(13 \%)$ & 0.306 \\
\hline Asthma & No & $100(100 \%)$ & $97(97 \%)$ & 0.081 \\
\hline & Yes & $0(0 \%)$ & $03(03 \%)$ & \\
\hline Cardiac problems & No & $90(90 \%)$ & $96(96 \%)$ & 0.297 \\
\hline & Yes & $10(10 \%)$ & $04(4 \%)$ & \\
\hline Lung involvement & & & & \\
\hline Unilateral (either right/ left lung involved) & No & $89(89 \%)$ & $87(87 \%)$ & \\
\hline & Yes & $11(11 \%)$ & $13(13 \%)$ & 0.663 \\
\hline Bilateral & No & $69(69 \%)$ & $23(23 \%)$ & \\
\hline
\end{tabular}




\begin{tabular}{|c|c|c|c|c|}
\hline & Yes & $31(31 \%)$ & 77(77\%) & 0.00 \\
\hline \multicolumn{5}{|l|}{ Disease distribution } \\
\hline \multirow[t]{2}{*}{ Peripheral } & No & $64(64 \%)$ & $33(33 \%)$ & \\
\hline & Yes & $36(36 \%)$ & $67(67 \%)$ & 0.00 \\
\hline \multirow[t]{2}{*}{ Central } & No & $92(92 \%)$ & $98(98 \%)$ & \\
\hline & Yes & $08(08 \%)$ & $02(02 \%)$ & 0.05 \\
\hline \multirow[t]{2}{*}{ Diffuse } & No & $98(98 \%)$ & $76(76 \%)$ & \\
\hline & Yes & $02(02 \%)$ & $24(24 \%)$ & 0.00 \\
\hline \multicolumn{5}{|l|}{ Involvement of Lobes } \\
\hline \multirow[t]{2}{*}{ Upper } & No & $96(96 \%)$ & $96(96 \%)$ & \\
\hline & Yes & $04(04 \%)$ & $04(04 \%)$ & 0.639 \\
\hline \multirow[t]{2}{*}{ Middle } & No & $80(80 \%)$ & $56(56 \%)$ & \\
\hline & Yes & $20(20 \%)$ & $44(44 \%)$ & 0.00 \\
\hline \multirow[t]{2}{*}{ Lower } & No & $66(66 \%)$ & $13(13 \%)$ & \\
\hline & Yes & $34(34 \%)$ & $87(87 \%)$ & 0.00 \\
\hline \multirow[t]{2}{*}{ Lymphadenopathy } & No & $97(97 \%)$ & $97(97 \%)$ & \\
\hline & Yes & $03(03 \%)$ & $03(03 \%)$ & 0.663 \\
\hline \multirow[t]{2}{*}{ Pleural effusion } & No & $90(90 \%)$ & $92(92 \%)$ & \\
\hline & Yes & $10(10 \%)$ & $08(08 \%)$ & 0.084 \\
\hline \multirow[t]{2}{*}{ Lung fibrosis } & No & $98(98 \%)$ & $97(97 \%)$ & \\
\hline & Yes & $02(02 \%)$ & $03(03 \%)$ & 0.651 \\
\hline \multicolumn{5}{|l|}{ Attenuation } \\
\hline \multirow[t]{2}{*}{ Ground glass appearance } & No & $70(70 \%)$ & $33(06 \%)$ & \\
\hline & Yes & $30(30 \%)$ & $67(94 \%)$ & 0.648 \\
\hline \multirow[t]{2}{*}{ Consolidation } & No & $78(78 \%)$ & $36(36 \%)$ & \\
\hline & Yes & $22(22 \%)$ & $64(64 \%)$ & 0.02 \\
\hline
\end{tabular}

every patient with clinical symptoms of fever, dry cough, sore throat is considered to be COVID-19 positive, until proven otherwise. This puts a huge constraint on already limited and stretched out healthcare system especially in a third world country. This also stresses the need to optimally use our diagnostic resources. Portable chest $X$-rays although having a sensitivity of $55 \%$ at $\leq 2$ days to $79 \%$ at $>11$ days $^{3,4}$ is still the primary investigation of choice in terms of feasibility and cost effectiveness with minimal risk of cross infection and exposure to the paramedical staff. It has its limitation regarding its inability to distinguish between COVID-19 and other COVID-19 mimickers purely on Chest X-ray findings. ${ }^{5}$ Although HRCT chest is the ideal radiological investigation of choice with sensitivity of $98 \%,{ }^{6}$ it is reserved for RT-PCR negative but symptomatic patients, patient's with COVID complications like pulmonary embolism and acute respiratory distress syndrome, and for follow up of post
COVID pulmonary fibrosis. CT chest is its own challenges regarding decontamination measures, affordability, and availability in primary health care centers and in terms of expert opinion. ${ }^{7}$

Our study showed that bilateral, peripheral distribution of middle and lower lobes ground glass haze or consolidation with no pleural effusion is significantly related to COVID-19 pneumonia which is consistent with other studies $^{8-11}$, however our study also showed that peripheral distribution was associated with an 11.08-fold risk in COVID-19 positive patients compared with diffuse distribution of other viral or bacterial pneumonias. Fig.1. Middle lobe involvement had four folds risk and lower lobe involvement had 11.04 folds risk in COVID-19 cases as compared to upper lobe involvement. Consolidation had 2.6 folds risk in COVID -19 positive cases. There are number of infectious diseases like atypical viral or fungal pneumonias that can mimic COVID-19 infection. There 
Table-II: Univariate analysis results.

(Figures are presented as whole numbers with percentages in brackets)

\begin{tabular}{|c|c|c|}
\hline Variables & Statistics & OR $(95 \% C I)$ \\
\hline Age (mean, SD) & $45 \pm 15.5$ & \\
\hline \multicolumn{3}{|l|}{ Gender } \\
\hline Female & $76(76 \%)$ & 1 \\
\hline Male & $24(24 \%)$ & $2.38(1.30,4.3) * * *$ \\
\hline \multicolumn{3}{|l|}{ Smoking History } \\
\hline No & $83(83 \%)$ & 1 \\
\hline Yes & $17(\%)$ & $.88(.63,1.89)$ \\
\hline \multicolumn{3}{|l|}{ Fever } \\
\hline No & $19(19 \%)$ & 1 \\
\hline Yes & $81(81 \%)$ & $2.5(1.31,3.6) * * *$ \\
\hline \multicolumn{3}{|l|}{ Cough } \\
\hline No & $38(38 \%)$ & 1 \\
\hline Yes & $62(62 \%)$ & $1.06(.80,1.41)$ \\
\hline \multicolumn{3}{|c|}{ Shortness of Breath } \\
\hline No & $55(55 \%)$ & 1 \\
\hline Yes & $45(45 \%$ & $1.22(.70,2.15)$ \\
\hline \multicolumn{3}{|l|}{ Sore Throat } \\
\hline No & $13(\%)$ & 1 \\
\hline Yes & $87(87 \%)$ & $1.88(1.17,3.04) * * *$ \\
\hline \multicolumn{3}{|l|}{ Loss of smell } \\
\hline No & $99(99 \%)$ & 1 \\
\hline Yes & $1(1 \%)$ & $.495(.04,5.54)$ \\
\hline \multicolumn{3}{|l|}{ Loss of taste } \\
\hline No & $96(96 \%)$ & 1 \\
\hline Yes & $4(4 \%)$ & $.67(.06,4.73)$ \\
\hline \multicolumn{3}{|l|}{ Travel History } \\
\hline No & $82(82 \%)$ & 1 \\
\hline Yes & $18(18 \%)$ & $1.81(1.20,2.72) * * *$ \\
\hline \multicolumn{3}{|l|}{ Diabetes } \\
\hline No & $94(94 \%)$ & 1 \\
\hline Yes & $06(6 \%)$ & $1.6(1.2,3.1) * *$ \\
\hline \multicolumn{3}{|l|}{ Hypertension } \\
\hline No & $38(38 \%)$ & 1 \\
\hline Yes & $62(62 \%)$ & $1.5(.87,2.6)$ \\
\hline \multicolumn{3}{|l|}{ Kidney Disease } \\
\hline No & $97(97 \%)$ & 1 \\
\hline Yes & $03(03 \%)$ & $1.3(.54,2.6)$ \\
\hline \multicolumn{3}{|l|}{ Tuberculosis } \\
\hline No & $87(87 \%)$ & 1 \\
\hline Yes & $03(03 \%)$ & $1.5(.59,3.8)$ \\
\hline \multicolumn{3}{|l|}{ Asthma } \\
\hline No & $97(97 \%)$ & 1 \\
\hline Yes & 03(03\%) & $.492(.427,8.34)$ \\
\hline \multicolumn{3}{|l|}{ Cardiac Problems } \\
\hline No & $96(96 \%)$ & 1 \\
\hline Yes & $04(04 \%)$ & $1.3(.71,2.6)$ \\
\hline
\end{tabular}

\begin{tabular}{|c|c|c|}
\hline \multicolumn{3}{|c|}{ Lung Involvement } \\
\hline Unilateral & $13(13 \%)$ & 1 \\
\hline Bilateral & $77(77 \%)$ & $7.4(2.7,8.6)^{\star \star * \star *}$ \\
\hline \multicolumn{3}{|c|}{ Disease distribution } \\
\hline Diffuse & $24(24 \%)$ & \\
\hline Peripheral & $67(67 \%)$ & $\begin{array}{c}11.08(5.03,15.08) \\
* * *\end{array}$ \\
\hline \multicolumn{3}{|c|}{ Involvement of lobes } \\
\hline Upper & $4(4 \%)$ & 1 \\
\hline Middle & $44(44 \%)$ & $4.23(1.73,5.8) * *$ \\
\hline Lower & $87(87 \%)$ & $11 \cdot 5(5.06,15.8) * * *$ \\
\hline \multicolumn{3}{|c|}{ Lymphadenopathy } \\
\hline No & $97(97 \%)$ & 1 \\
\hline Yes & $03(03 \%)$ & $.87(.67,2.2)$ \\
\hline \multicolumn{3}{|c|}{ Pleural effusion } \\
\hline No & $92(92 \%)$ & 1 \\
\hline Yes & $08(08 \%)$ & $1.1(.60,1.94)$ \\
\hline \multicolumn{3}{|c|}{ Lung Fibrosis } \\
\hline No & $97(97 \%)$ & 1 \\
\hline Yes & $03(03 \%)$ & $1.5(.248,3.79)$ \\
\hline \multicolumn{3}{|c|}{ Ground glass } \\
\hline appearanc & $67(67 \%)$ & 1 \\
\hline $\begin{array}{l}\text { No } \\
\text { Yes }\end{array}$ & $33(33 \%)$ & $1.07(.79,1.45)$ \\
\hline \multicolumn{3}{|c|}{ Consolidation } \\
\hline No & $36(36 \%)$ & 1 \\
\hline Yes & $64(64 \%)$ & $2.6(1.09,3.2) * *$ \\
\hline
\end{tabular}

are also numbers of noninfectious diseases like pulmonary edema, hemorrhage, alveolar proteinosis, interstitial lung disease, organizing pneumonias or aspiration pneumonias that can be difficult to differentiate from COVID-19

Table-III: Multivariate Analysis-Relationship between X-Ray findings and COVID-19 status of patients.

\begin{tabular}{|c|c|c|}
\hline Variables & Statistics & OR $(95 \% C I)$ \\
\hline \multicolumn{3}{|c|}{ Involvement of lobes } \\
\hline Upper & $4(4 \%)$ & 1 \\
\hline Middle & $44(44 \%)$ & $4.1(2 \cdot 3,5.1) * * *$ \\
\hline lower & $87(87 \%)$ & $11.5(5.06,15.8) * * *$ \\
\hline \multicolumn{3}{|c|}{ Disease Distribution } \\
\hline Diffuse & $24(24 \%)$ & 1 \\
\hline Peripheral & $67(67 \%)$ & $11.08(6.23,16.1) * * *$ \\
\hline \multicolumn{3}{|c|}{ Consolidation } \\
\hline No & $36(36 \%)$ & 1 \\
\hline Yes & $64(64 \%)$ & $2.6(1.09,3.2) * * *$ \\
\hline
\end{tabular}

Final model adjusted for age, gender, all symptoms, and co morbidities sequentially. ***highly significant statistically, CI, Confidence interval, OR Odds Ratio. 


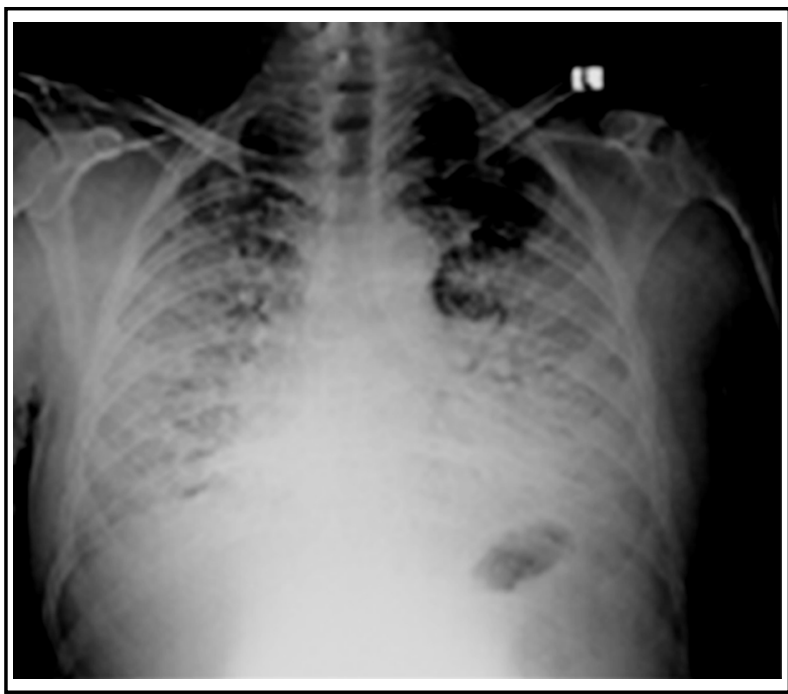

Fig.1: Chest $X$-ray of a COVID positive, middle aged female patient showing homogenous consolidation in bilateral lung fields predominantly in peripheral distribution in mid and lower zones with obscuration of cardiac and diaphragmatic silhouette and costophrenic angles on both sides. Patient had an acute episode of fever, shortness of breath and cough with no positive contact history.

infection on chest $\mathrm{X}$-rays. There are studies ${ }^{5,12}$ to differentiate between these diseases on CT chest findings but literature on chest X-rays is lacking. In our study patients with Radiological findings were described according to Fleischner Society glossary of terms for Thoracic imaging. ${ }^{13}$ Ground glass opacities were defined as increased opacification of lung parenchyma not obscuring blood vessels and bronchi. Consolidation was described as homogenous opacification of lung parenchyma obscuring blood vessels and bronchi.

Viral pneumonias show chest $\mathrm{X}$ - ray findings of unilateral or bilateral ground glass haze, patchy consolidations, bronchial wall thickening, reticulonodular infiltrates and small pleural effusions. ${ }^{12}$ COVID-19 pneumonia, severe acute respiratory syndrome virus (SARS) and middle east respiratory syndrome virus (MERS) all show subpleural distribution of consolidation or ground glass haze while there is generally absence of cavitation, pleural effusion and pneumothorax in COVID and SARS. ${ }^{14-16}$ Tuberculosis is the most common pulmonary infection in our subcontinent. Chest Xray finding of pulmonary tuberculosis are lobar or multilobar cosolidations, bronchopneumonias, pleural effusions, lymphadenopathy, miliary tubercles, cavitating

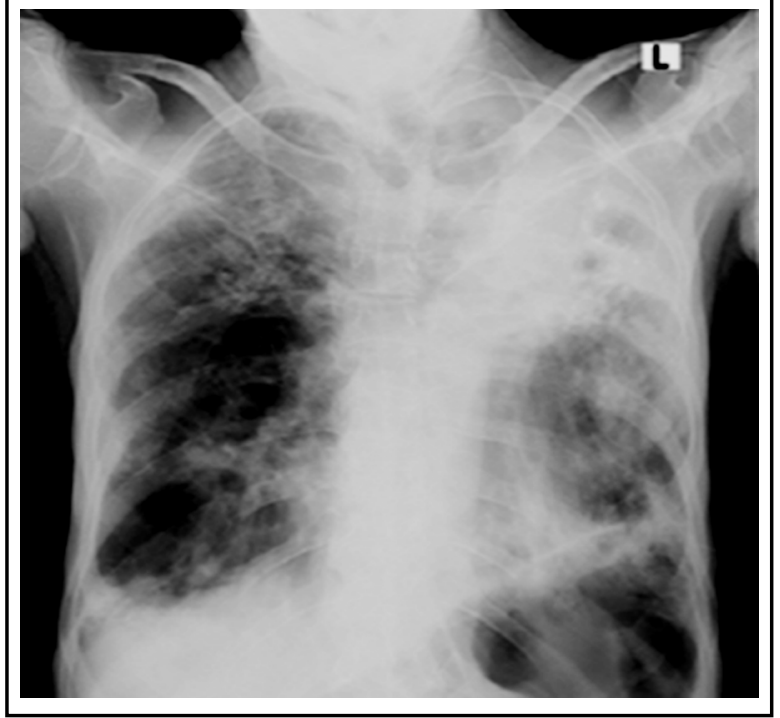

Fig.2. Chest $X$-ray of a young male patient, having cough, sore throat, rhinitis, shortness of breath and fever but had negative COVID serology. X-ray showed left upper lobe collapse, fibrocalcific changes, atelactatic bands in left lower zone, elevation of ipsilateral hemidiaphragm with few calcific granulomas in right middle zone, these are sequelae of healed pulmonary koch's. (Consistent with History) In homogenous airspace shadowing in both upper and right mid zones, bilateral pleural effusions suggestive of acute overwhelming infection on background of chronic healed granulomatous disease. Patient was advised for gene expert test to rule out reactivation of pulmonary Koch's.

lesions with bilateral upper lobe predilections. Ground glass haze is not a feature of pulmonary tuberculosis. ${ }^{17} \quad$ Fig.2. $\quad$ Fungal pneumonias usually occur in immunocompromised patients. They may show cavitating lesion with fungus ball (air meniscus sign), dilated bronchi with gloved finger appearance or in cases of invasive aspergillosis areas of ground galls haze, cavitating consolidations, pleural effusions and lymph adenopathy. There is no zonal predilection. ${ }^{18}$

Interstitial lung disease tops the differential for COVID-19 infection. Patients with non-specific interstitial pneumonia and desquamative interstitial pneumonia may be indistinguishable from COVID-19 on chest X-ray findings alone as they also present with bilateral peripheral areas of ground glass haze with middle and lower zonal predominance. Patients of NSIP would have progressive history of dyspnea, CT chest findings of reticular opacities with subpleural sparing and volume loss. Patients with DIP would be chronic smokers with CT chest finding of bilateral reticular opacities and emphysematous 
changes. Hypersensitivity pneumonitis is another differential to be considered with Chest $\mathrm{X}$-ray showing bilateral peripheral ground glass haze/consolidations with fine reticulations, however there are also poorly defined small nodular opacities sometimes sparing apices and bases. ${ }^{19}$

Patients with congestive cardiac failure and pulmonary edema show Chest Xray findings of cardiomegaly, upper lobe blood diversion, Kerly A and B lines, bat wing consolidation with air bronchograms, bilateral pleural effusions, interlobar thickening and peribronchial cuffing making it distinguishable from COVID-19 pneumonia. Patients with pulmonary hemorrhage will have history of collagen vascular diseases, trauma or anticoagulation therapy history. Chest X-ray finding would be of focal, multifocal areas of ground glass haze or consolidation with cavitations, pleural effusions with no zonal or lobar predilection.

Chest Xray findings of alveolar proteinosis are widespread nodular or reticulo nodular opacities or consolidation with relative apical and costophrenic angle sparing, but pleural effusions and lymph adenopathy is usually not a feature of this disease.

Organizing pneumonias show chest X-ray findings of bilateral subpleural., diffuse or patchy consolidations or reticulonodular opacities, ${ }^{20}$ while drug induced organizing pneumonias may have varied findings such as wide spread consolidation, with interstitial fibrosis. ${ }^{21}$ Patients with aspiration pneumonia will have a preexisting condition and show patch infiltrate in dependent lung segments with pleural effusions and cavitation.

Limitations of the Study: It is a study retrospective with small sample size. Chest $X$-ray severity index was not calculated and there was no co-relation between chest X-ray findings and CT chest findings., ${ }^{32-24}$ There should be more comprehensive studies to differentiate between infectious and non-infectious COVID-19 radiological mimickers.

Another limitation was absence of serial CXRs to see progression of disease in terms of its resorptive phase and pulmonary fibrosis in our population..$^{25}$ Clinical significance of this study to guide our general practitioners, clinicians, radiologists and paramedical health care workers especially working in primary health centers and clinics to diagnose COVID-19 on chest X-ray findings alone. ${ }^{26,27}$ The awareness and knowledge of diseases that mimic COVID-19 on chest X-rays can help in early management of these diseases and prevent unnecessary wastage of resources in times of pandemic.

\section{CONCLUSION}

Bilateral, peripheral distribution of middle and lower lobes ground glass haze or consolidation with no pleural effusion is significantly related to COVID-19 pneumonia. Overlapping imaging features of the infectious and non-infectious COVID mimickers can be further ironed out/ excluded by detailed clinical evaluation and further radiological workup.

Conflict of Interest: None.

Grant Support \& Financial Disclosures: None.

\section{REFERENCES}

1. Durrani M, Kalsoom U, Yousaf A. Chest X-rays findings in COVID-19 patients at a University Teaching Hospital A descriptive study. Pak J Med Sci. 2020;36(COVID19-S4): S22-S26. doi: 10.12669/pjms.36.COVID19-S4.2778

2. Sverzellati N, Ryerson CJ, Milanese G, Renzoni EA, Volpi A, Spagnolo $P$, et al. Chest $x$-ray or CT for COVID-19 pneumonia? Comparative study in a simulated triage setting. Eur Respir J. 2021;2004188. doi: 10.1183/13993003.04188-2020

3. Jacobi A, Chung M, Bernheim A, Eber C. Portable chest X-ray in coronavirus disease-19 (COVID-19): A pictorial review. Clin Imaging. 2020;64:35-42. doi: 10.1016/j. clinimag.2020.04.001

4. Cozzi D, Albanesi M, Cavigli E, Moroni C, Bindi A, Luvara S, et al. Chest X-ray in new Coronavirus Disease 2019 (COVID-19) infection: Findings and correlation with clinical outcome. Radiol Medica. 2020;125(8):730-737. doi: 10.1007/s11547-020-01232-9

5. Duzgun SA, Durhan G, Demirkazik FB, Akpinar MG, Ariyurek OM. COVID-19 pneumonia: The great radiological mimicker. Insights Imaging. 2020;11(1):118. doi: 10.1186/s13244-020-00933-z

6. Aljondi R, Alghamdi S. Diagnostic value of imaging modalities for COVID-19: Scoping review. J Med Internet Res. 2020;22(8):19673. doi: 10.2196/19673

7. Zhou Z, Guo D, Li C, Fang Z, Chen L, Yang R, et al. Coronavirus disease 2019: Initial chest CT findings. Eur Radiol. 2020;2(8):4398-4406. doi: 10.1007/s00330-02006816-7

8. Li X, Fang X, Bian Y, Lu J. Comparison of chest CT findings between COVID-19 pneumonia and other types of viral pneumonia: A two-center retrospective study. Eur Radiol. 2020;30(10):5470-5478

9. Shi H, Han X, Jiang N, Cao Y, Alwalid O, Gu J, et al. Radiological findings from 81 patients with COVID-19 pneumonia in Wuhan, China: A descriptive study. Lancet Infect Dis. 2020;20(4):425-434. doi: 10.1016/S14733099(20)30086-4 
10. Bernheim A, Mei X, Huang $M$, et al. Chest CT Findings in Coronavirus Disease-19 (COVID-19): Relationship to Duration of Infection. Radiology. 2020;295(3):200463. doi: 10.1148 / radiol.2020200463

11. Ming-Yen N, YP LE, Jin Y, Fangfang Y, Xia L, Hongxia W. Imaging Profile of the COVID-19 Infection: Radiologic Findings and Literature Review. Radiol Cardiothorac Imaging. 2020;2(1):1-8. doi: 10.1148/ryct.2020200034

12. Franquet T. Imaging of pulmonary viral pneumonia. Radiology. 2011;260(1):18-39. doi:10.1148/ radiol.11092149/-/DC1

13. Hansell DM, Bankier AA, MacMahon H, McLoud TC, Muller NL, Remy J. Fleischner Society: Glossary of terms for thoracic imaging. Radiology. 2008;246(3):697-722.

14. Ajlan AM, Ahyad RA, Jamjoom LG, Alharthy A, Madani TA. Middle East respiratory syndrome coronavirus (MERS$\mathrm{CoV}$ ) infection: Chest CT findings. Am J Roentgenol. 2014;203(4):782-787. Middle East Respiratory Syndrome Coronavirus (MERS-CoV) Infection: Chest CT Findings. doi: 10.2214/AJR.14.13021

15. Choi WJ, Lee KN, Kang EJ, Lee H. Middle east respiratory syndrome-coronavirus infection: A case report of serial computed tomographic findings in a young male patient. Korean J Radiol. 2016;17(1):166-170. doi: 10.3348/ kjr.2016.17.1.166

16. Das KM, Lee EY, Al Jawder SE, Enani MA, Singh R, Skakni L, et al. Acute middle east respiratory syndrome coronavirus: Temporal lung changes observed on the chest radiographs of 55 patients. Am J Roentgenol. 2015;205(3):W267-W274. doi: 10.1186/s12890-020-01286-5

17. Basem Abbas Al U. The Radiological Diagnosis of Pulmonary Tuberculosis (TB) in Primary Care. J Fam Med Dis Prev. 2018;4(1):1-7. doi: 10.23937/2469-5793/1510073

18. Inayati AM. Diagnostic Test of Chest Radiograph on Fungal Pneumoniae. 2021;33(ICoSIHSN 2020):228-233. doi: 10.2991/ahsr.k.210115.048

19. Hodgson MJ, Parkinson DK, Karpf M. Chest X-rays in hypersensitivity pneumonitis: A metaanalysis of secular trend. Am J Ind Med. 1989;16(1):45-53. doi: 10.1002/ ajim. 4700160106

20. Lee JW, Lee KS, Lee HY, Chung MP, Yi CA, Kim TS, et al. Cryptogenic organizing pneumonia: Serial highresolution CT findings in 22 patients. Am J Roentgenol. 2010;195(4):916-922. doi: 10.2214/ AJR.09.3940
21. Gemma A. Drug-induced interstitial lung disease. Gan To Kagaku Ryoho. 2008;35(10):1668-1670.

22. Tsakok M, Shaw R, Murchison A, Ather S, Xie C, Watson $\mathrm{R}$, et al. Diagnostic accuracy of initial chest radiograph compared to SARS-CoV-2 PCR in patients with suspected COVID-19. BJR|Open. 2020;2(1):20200034. doi: 10.1259/ bjro. 20200034

23. Wong HYF, Lam HYS, Fong AHT, Leung ST, Chin TWY, Lo CSY, et al. Frequency and Distribution of Chest Radiographic Findings in COVID-19 Positive Patients. Radiology. 2020; 296(2):E72-E78. doi: 10.1148/ radiol.2020201160

24. Cleverley J, Piper J, Jones MM. The role of chest radiography in confirming covid-19 pneumonia. BMJ. 2020;370:m2426. doi: $10.1136 /$ bmj.m2426

25. Rousan LA, Elobeid E, Karrar M, Khader Y. Che x-ray findings and temporal lung changes in patients with COVID-19 pneumonia. BMC Pulm Med. 2020;20(1):1-9. doi: 10.1186/s12890-020-01286-5

26. Cozzi D, Albanesi M, Cavigli E, Moroni C, Bindi A, Luvarà $S$, et al. Chest X-ray in new Coronavirus Disease 2019 (COVID-19) infection: Findings and correlation with clinical outcome. Radiol Medica. 2020;125(8):730737. doi: 10.1007/s11547-020-01232-9

27. Nishtar T, Noor N, Khan SL. X-ray patterns of COVID-19 in patients presenting to Lady Reading Hospital, Peshawar, Pakistan. Pak J Med Sci. 2021;37(1):28-33. doi: 10.12669/ pjms.37.1.3435

\section{Authors' Contribution:}

MD: Conceived, designed, manuscript writing and is responsible for integrity of the study.

UK: Did data collection and manuscript writing. AS \& IUH: Designed methodology, performed statistical analysis and editing of manuscript.

AY \& SN: Data collection.
Authors:

1. Dr. Misbah Durrani, MCPS. FCPS. MHPE.

2. Dr. Afshan Shahid, MPH, MSc, FCPS. Associate Professor Community Medicine, SIMS Lahore, Pakistan.

3. Dr. Ume Kalsoom, FCPS. Assistant Professor, RMU

4. Dr. Inam ul Haq, FCPS. MHPE. Associate Professor, Al-Shifa Trust Eye Hospital, Rawalpindi, Pakistan.

5. Dr. Anum Yousaf, MBBS

6. Dr. Saqib Naveed, MBBS

5,6: Residents, Department of Diagnostic Radiology, Benazir Bhutto Hospital, Rawalpindi, Pakistan. 